\title{
Perfusion techniques in the preservation of the isolated canine lung
}

\author{
D. B. C L A R K E \\ From the Queen Elizabeth Hospital, Birmingham
}

\begin{abstract}
An experimental technique is described whereby the isolated lung is perfused by means of its respiratory excursion. No perfusion pump is required. Lungs were subjected to positive and negative pressure inflation in a sealed box and were perfused with either blood or blood and low molecular weight dextran at $36^{\circ} \mathrm{C}$. and $23^{\circ} \mathrm{C}$. In all experiments gross histological changes and pulmonary oedema developed within four hours. Marginally longer perfusions were obtained than in a control series in which a roller pump was used.
\end{abstract}

The preservation of the isolated lung in a viable state constitutes an important part of any homotransplantation programme, but the use of perfusion has always been attended by the development of pulmonary oedema after one to six hours. A solution has yet to be found to explain this phenomenon which occurs with different perfusates and at different temperatures. In an attempt to exclude the roller pump as a cause of oedema a method has been devised in which the lung is perfused by using its respiratory excursion as a means of propelling the perfusate through the vascular bed.

\section{METHODS AND MATERIALS}

Dogs were anaesthetized by an intravenous injection of nembutal and a left thoracotomy was performed. Heparin, $1.5 \mathrm{mg}$. $/ \mathrm{kg}$., was administered and the dog was bled by means of a tube inserted into the apex of the left ventricle. The left lung was removed by dividing the pulmonary artery and bronchus and excising that portion of the left atrium surrounding the orifices of the left pulmonary veins.

The lung was mounted in an airtight Perspex box. The bronchus was attached to a cannula which passed through the lid, and the pulmonary vessels were connected to other cannulae which were led to a reservoir (Fig. $1 \mathrm{a}, \mathrm{b}$ ). The inflow and outflow ports of the reservoir were guarded by flap valves which ensured a unidirectional flow in the system. The reservoir contained a heat exchanger. The system was primed with either fresh autologous blood or blood diluted with low molecular weight dextran in a ratio of 4 parts blood to 1 part diluent.

A reciprocating air pump with a positive/negative phase was connected to a further cannula in the lid of the box and the lung was ventilated at 18 cycles/ min. with a tidal volume varying from 250 to 400 $\mathrm{ml}$. The tidal volume selected was determined by the size of the dog and was that volume judged to give a physiological range of respiratory excursion. The average time between cardiac arrest and the onset of perfusion was 20 minutes.

The lung inspired a $97 \%$ oxygen $3 \%$ carbon dioxide mixture, which was found to maintain the $\mathrm{PcO}_{2}, \mathrm{pH}$, and bicarbonate levels of the prime at normal values. Pressures were recorded in the pulmonary artery, pulmonary vein, and in the box. Blood temperatures and blood gas levels were monitored.

As the lung expanded under the influence of the negative pressure applied to the box, gas was drawn into the bronchus, and at the same time blood was drawn from the reservoir into the pulmonary vascular bed by way of the cannula leading to the pulmonary artery. When the lung was deflated during the positive pressure phase of the cycle blood was expelled from the pulmonary veins back to the reservoir. Thus a circulation was produced by the inflation and deflation of the lung. Studies of the passage of dyes and $x$-ray contrast media confirmed that this was a true circulation and not merely an ebb and flow of blood with respiration (Fig. 2). The reservoir was calibrated and, by observing the rise and fall of the level of blood within it with each inflation of the lung, the flow could be calculated. Flows of the order of $150-200 \mathrm{ml} . / \mathrm{min}$. were obtained with this method, which was studied in five lungs (Table).

A second method of producing pulmonary perfusion without a vascular pump was obtained by applying intermittent positive pressure ventilation to the bronchus and inflating the lung against the resistance of a toy balloon connected to the box. As the lung was inflated against resistance, blood was expelled from the pulmonary veins into the reservoir. During deflation blood ran from the reservoir into the pulmonary artery under the influence of gravity. The reservoir was mounted $15 \mathrm{~cm}$. above the hilum 


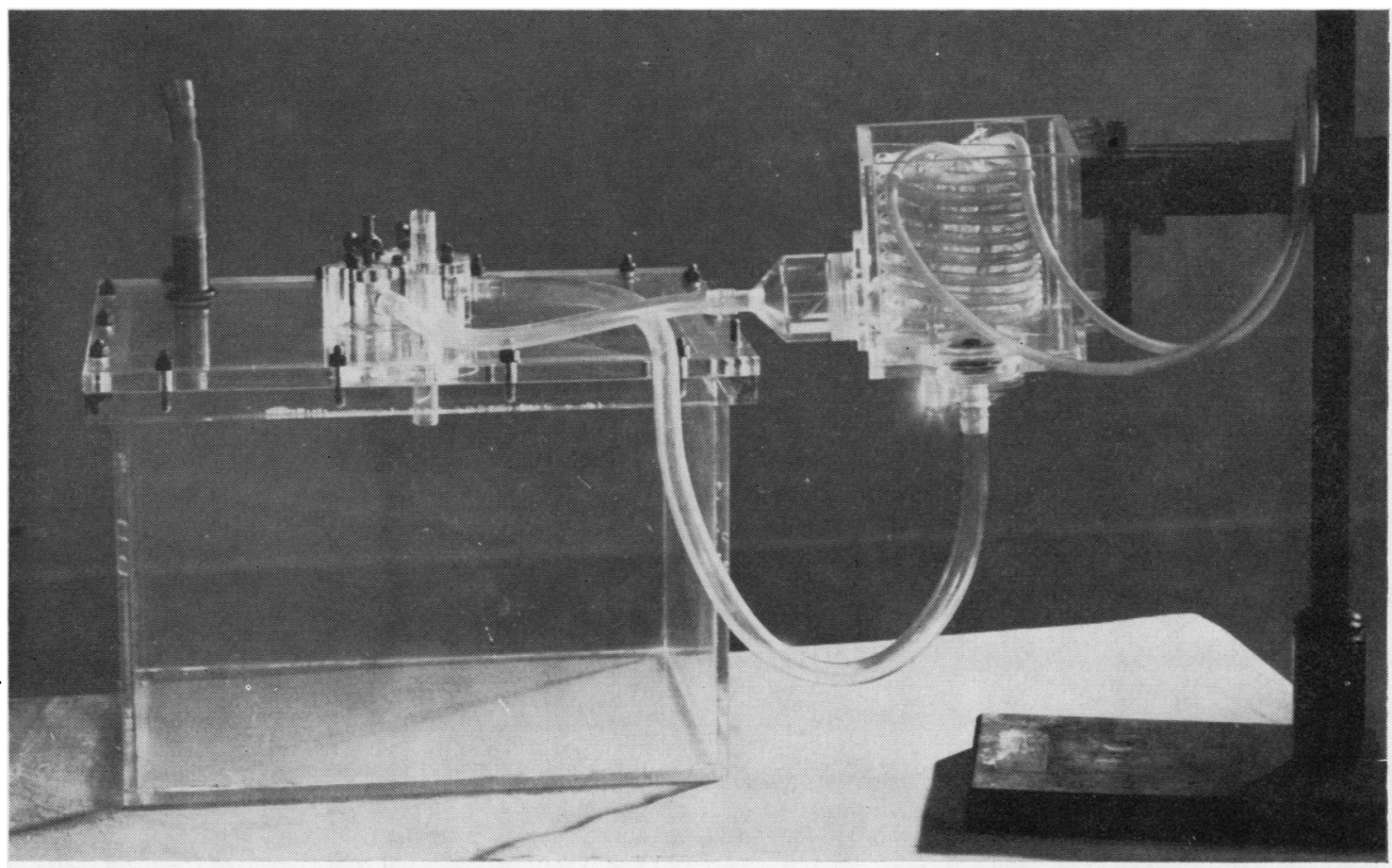

(a)

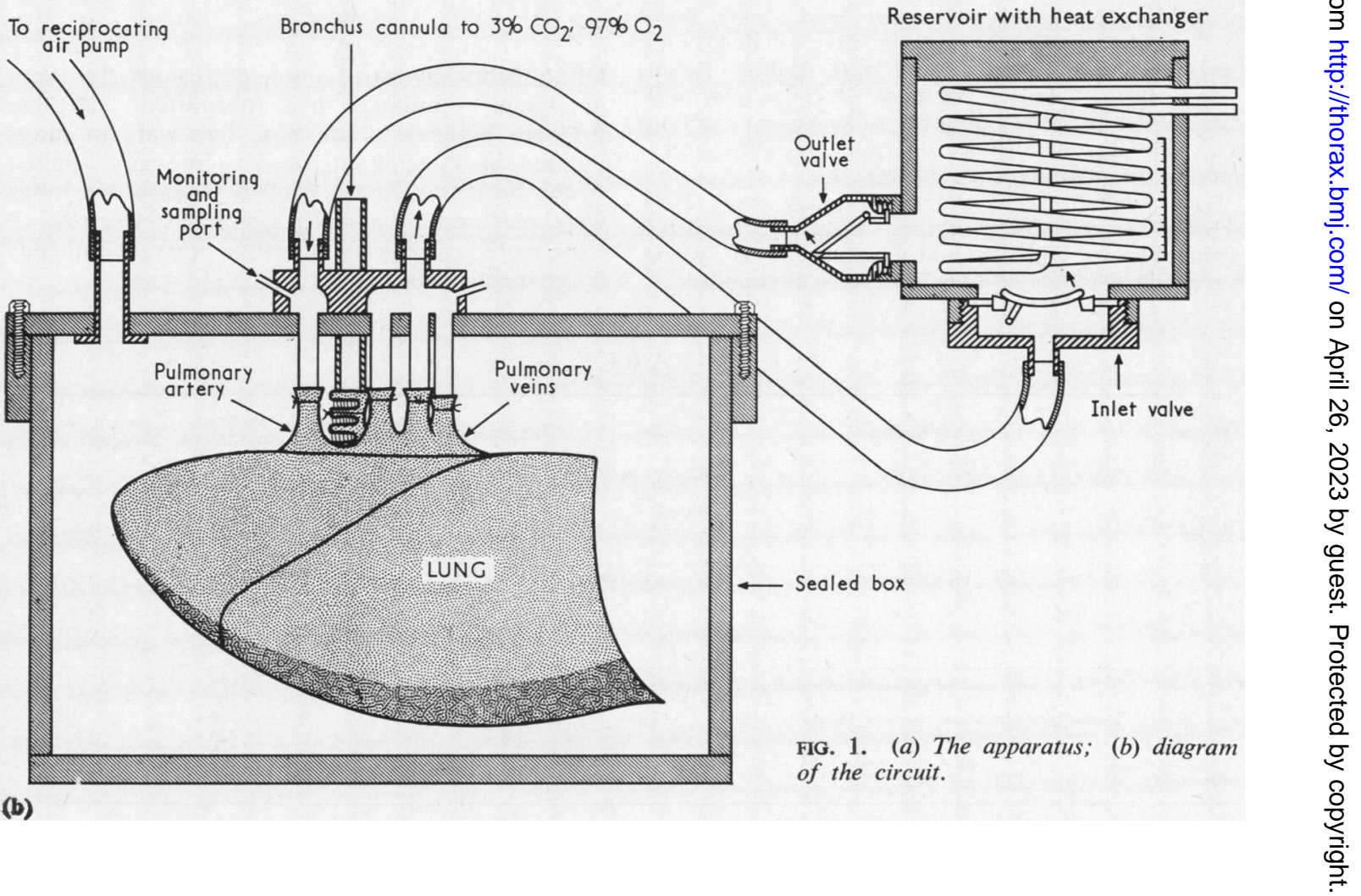




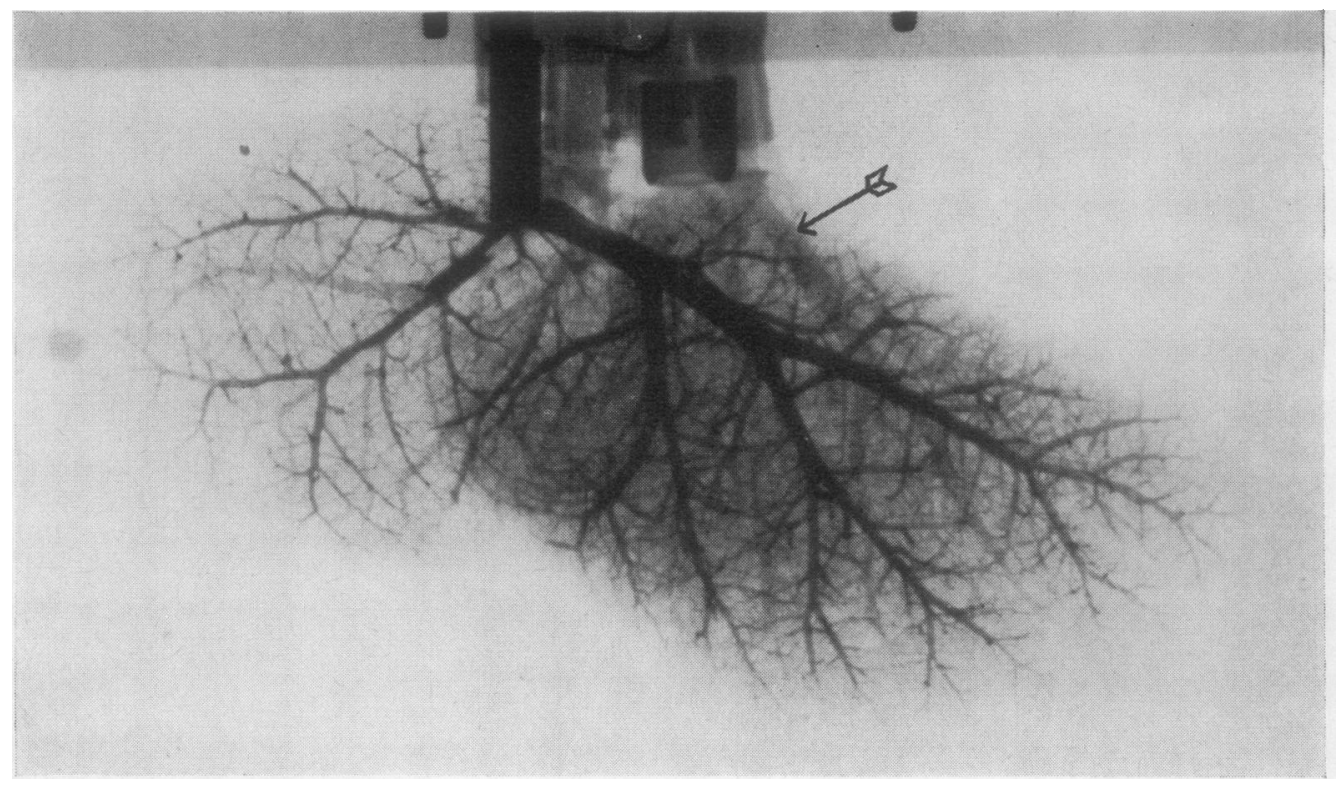

FIG. 2. Angiogram obtained by injection of contrast medium into the reservoir. Note the filling of the pulmonary veins (arrowed) indicating that a true circulation is produced. (Photograph taken 2 seconds after completion of the injection of contrast medium.)

of the lung to provide a pressure head. Again, flows of the order of $150-200 \mathrm{ml} . / \mathrm{min}$. were obtained. Five lungs perfused by this method were studied (Table).

In a further control group of six lungs, perfusion was carried out with a deBakey roller pump ; the lung was ventilated with either intermittent positive pressure or negative pressure (Table).

The metabolic needs of lung tissue are small. They account for only $0.7 \%$ of total oxygen consumption (Fritts, Strauss, Wichern, and Cournand, 1963). Blood traversing the isolated lung was fully oxygenated.

\section{RESULTS}

Of 16 technically satisfactory perfusions, five were in lungs ventilated by intermittent negative pressure applied to the box, five were in lungs inflated by intermittent positive pressure applied to the bronchus, and a control series of six lungs were perfused by a roller pump system; two of these were ventilated by negative pressure and four by positive pressure.

T A B L E

\begin{tabular}{|c|c|c|c|c|c|c|c|c|c|}
\hline Lung & \multicolumn{4}{|c|}{ Type of Perfusion } & Prime & Temperature & $\begin{array}{c}\text { Mounting } \\
\text { Position }\end{array}$ & $\begin{array}{l}\text { Perfusion } \\
\text { (ml./min.) }\end{array}$ & $\begin{array}{l}\text { Time to Onset of } \\
\text { Oedema (min.) }\end{array}$ \\
\hline $\begin{array}{l}1 \\
2 \\
3 \\
4 \\
5\end{array}$ & $\begin{array}{r}\text { Negati } \\
\text {,, } \\
\text {," } \\
\text {," }\end{array}$ & $\begin{array}{l}\text { essu } \\
\text {,", } \\
\text {,", }\end{array}$ & $\begin{array}{l}\text { tilation } \\
\text {," } \\
\text {," }\end{array}$ & & $\begin{array}{l}\text { Blood/LMWD } \\
\text { Blood", } \\
\text {,", }\end{array}$ & $\begin{array}{l}23^{\circ} \mathrm{C} . \\
23^{\circ} \mathrm{C} . \\
23^{\circ} \mathrm{C} . \\
36^{\circ} \mathrm{C} . \\
36^{\circ} \mathrm{C} .\end{array}$ & $\begin{array}{c}\text { Horizontal } \\
\text {," } \\
\text { Vertical } \\
\text {,, }\end{array}$ & $\begin{array}{r}250 \\
130 \\
150 \\
60 \\
170\end{array}$ & $\begin{array}{r}120 \\
90 \\
75 \\
120 \\
90\end{array}$ \\
\hline $\begin{array}{l}1 \\
2 \\
3 \\
4 \\
5\end{array}$ & $\begin{array}{r}\text { Positiv } \\
\text {," } \\
\text {," }\end{array}$ & $\begin{array}{r}\text { ssur } \\
\text {,", } \\
\text {,", }\end{array}$ & $\begin{array}{l}\text { ilation } \\
\text {," } \\
\text {," }\end{array}$ & & $\begin{array}{l}\text { Blood/LMWD } \\
\text {,", } \\
\text { Blood", } \\
\text {,, }\end{array}$ & $\begin{array}{l}23^{\circ} \mathrm{C} . \\
36^{\circ} \mathrm{C} . \\
36^{\circ} \mathrm{C} . \\
36^{\circ} \mathrm{C} . \\
36^{\circ} \mathrm{C} .\end{array}$ & $\begin{array}{l}\text { Horizontal } \\
\text { Vertical } \\
\text { Horizontal }\end{array}$ & $\begin{array}{l}120 \\
140 \\
300 \\
112 \\
170\end{array}$ & $\begin{array}{r}120 \\
60 \\
150 \\
150 \\
90\end{array}$ \\
\hline $\begin{array}{l}1 \\
2 \\
3 \\
4 \\
5 \\
6\end{array}$ & \multicolumn{4}{|c|}{$\begin{array}{l}\text { Roller pump/negative pressure inflation } \\
\text { Roller pump/positive pressure inflätion }\end{array}$} & $\begin{array}{c}\text { Blood } \\
\text {, } \\
\text {, } \\
\text { ", }\end{array}$ & $\begin{array}{l}36^{\circ} \mathrm{C} . \\
23^{\circ} \mathrm{C} . \\
36^{\circ} \mathrm{C} . \\
36^{\circ} \mathrm{C} . \\
36^{\circ} \mathrm{C} . \\
36^{\circ} \mathrm{C} .\end{array}$ & $\begin{array}{c}\text { Horizontal } \\
\text {," } \\
\text { ", } \\
\text { Vertical }\end{array}$ & $\begin{array}{l}120 \\
300 \\
160 \\
220 \\
260 \\
180\end{array}$ & $\begin{array}{r}90 \\
75 \\
50 \\
120 \\
90 \\
240\end{array}$ \\
\hline
\end{tabular}


Pulmonary oedema developed in all lungs within four hours. This is first manifested as a failure of the lung to collapse completely if the pressure in the box is restored to atmospheric level. After about 15 minutes crackling sounds can be heard on listening over the open bronchus and eventually bloody froth is expelled from the bronchus and can be expressed from the cut surface of the lung. Subpleural haemorrhages were also seen. Loss of blood into lung tissue was shown by the depletion of blood in the reservoir. Histological examination revealed rupture of capillaries, extravasation of blood into the alveoli and alveolar septae, and a cuff of haemorrhage surrounding the smaller pulmonary vessels (Fig. 3). This process is more than the simple transudation of fluid that occurs in pulmonary oedema and represents gross destruction of pulmonary capillaries. The only comparable pictures seen in human pathology are those found in cold injury in children, where an overgenerous pulmonary-systemic anastomosis has

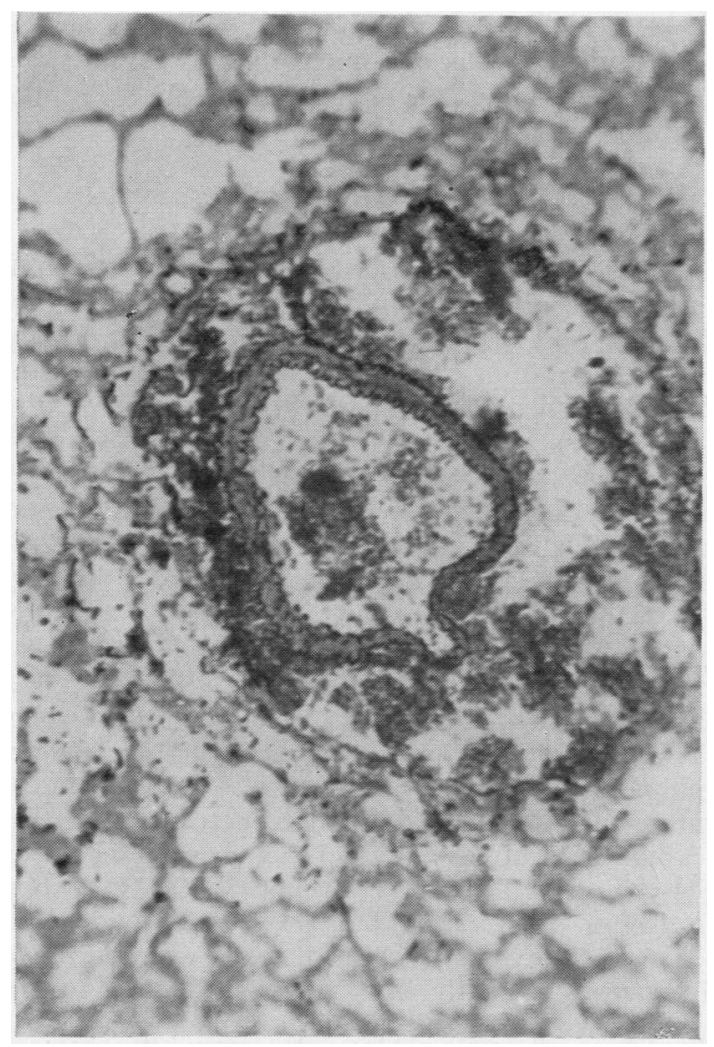

FIG. 3. Histological appearance of perfused lung showing perivascular cuff of haemorrhage. been created in the treatment of Fallot's tetralogy, and in some deaths after cardiopulmonary bypass.

In the lungs perfused by negative pressure inflation (group I) the average time taken for the first signs of pulmonary oedema, as defined, to develop was 100 minutes. Pressures within the pulmonary artery were less than $30 \mathrm{~mm}$. $\mathrm{Hg}$ until the onset of oedema, when they rose sharply (Fig. 4).

Those perfusions in which a circulation was obtained by positive-pressure inflation of the lung (group II) displayed a similar range of pulmonary artery pressures, but the terminal elevation in pressure was not seen. The average time to the onset of oedema in this group was 105 minutes. Flows of the order of $150-200 \mathrm{ml} / \mathrm{min}$. were obtained in both group I and group II (Fig. 5).

In the control group (group III) flow rates were restricted to $200 \mathrm{ml}$./ $\mathrm{min}$. It was found that higher flows produced pulmonary artery pressures in excess of $40 \mathrm{~mm}$. Hg. Four of the six lungs in this group were inflated by positive pressure and two by negative pressure. The average time to the onset of oedema was 110 minutes. Those inflated by negative pressure developed changes within 85 minutes, while the average time to the onset of oedema in the group ventilated by positive pressure was 125 minutes.

In all groups intrabronchial and pulmonary vein pressures were maintained within physiological limits (Fig. 6).

The conditions of the experiments were varied in an attempt to find the optimum circumstances for prolonged perfusions.

VARIATION IN TEMPERATURE OF PERFUSATES Eleven lungs were perfused at $36^{\circ} \mathrm{C}$. and five at $23^{\circ} \mathrm{C}$. The average time to the onset of pulmonary oedema was 122 minutes in the former and 95 minutes in the latter.

VARIATION IN MOUNTING POSITION OF THE LUNG Eleven lungs were mounted in the horizontal position and five were mounted vertically. West, Dollery, and Naimark (1964) have demonstrated that blood flow is greatest in the more dependent portions of the lungs. The average time to the onset of oedema was 168 minutes in the vertical group and 88 minutes in those mounted horizontally.

VARIATION IN THE TYPE OF PERFUSATES Five lungs were perfused with a mixture of blood and low molecular weight dextran in the ratio of $4: 1$. Pulmonary oedema developed on average at 126 

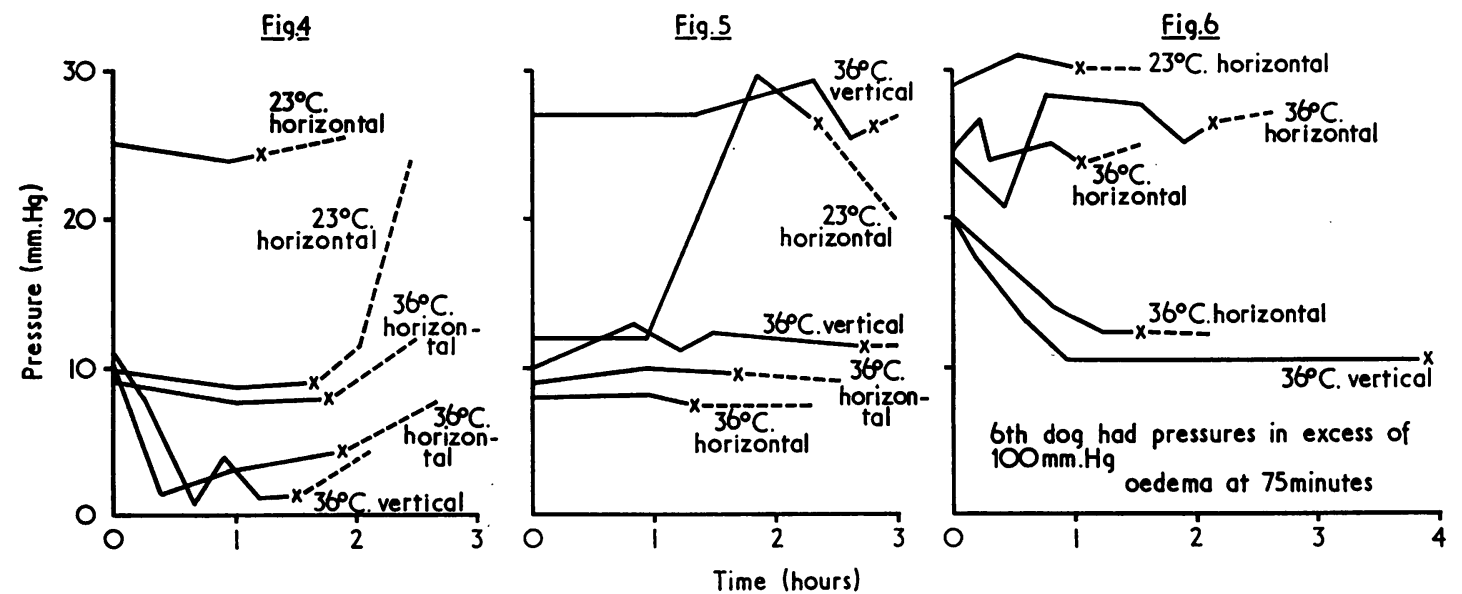

Time (hours)

FIG. 4. Pulmonary artery pressures in lungs perfused by negative pressure inflation. The crosses indicate the onset of pulmonary oedema.

FIG. 5. Pulmonary_artery pressures in lungs perfused by positive pressure inflation.

FIG. 6. Pulmonary artery pressures in lungs perfused by a roller pump.

minutes in the group. Eleven lungs were perfused with fresh homologous blood with heparin as the anticoagulant. In these the average time to the onset of oedema was 107 minutes.

Daly, Linzell, Mount, and Waites (1954) pointed out that stimulation of the sympathetic nerve supply of the lung produces pulmonary vasoconstriction. In some lungs the vagal fibres leading to the hilum were dissected out and stimulated at 30 cycles/min., a frequency which has been found to be effective in initiating peristalsis. In no case was any alteration observed in the pulmonary artery pressure, and no improvement in the duration of perfusion was achieved. Halpern, Hamburger, and Cruchaud (1948) reported that antihistamines prevented the development of pulmonary oedema induced by thiodiphenylamine. Promethazine hydrochloride (Phenergan) was introduced into the perfusate in some of the preparations, but again there was no alteration in vascular or respiratory pressures and no improvement in perfusion.

Had oedema developed because of arteriovenous shunting with hypoxia of the capillaries distal to the shunts? The $\mathrm{Po}_{2}$ of the inflating gases and the pulmonary venous blood was estimated, but no gradients could be demonstrated until gross oedema of the lung had developed, when gradients of the order of $100 \mathrm{~mm}$. $\mathrm{Hg}$ were obtained. This implies that shunting does not occur in the perfused lung. Impairment of the ability of the oedematous lung to oxygenate the blood passing through it was demonstrated by recharging the reservoir with deoxygenated blood at intervals and determining the $\mathrm{PO}_{2}$ gradient between the pulmonary artery and veins.

\section{DISCUSSION}

The isolated perfused lung has long been a tool of the experimental physiologist, but few perfusions were prolonged and there is little record of the condition of the lung at the conclusion of the experiment. During the early days of cardiopulmonary bypass the isolated dog or monkey lung was used as an oxygenator. Pulmonary oedema developed during the first hour of perfusion, but gaseous exchange was still possible for a further three to four hours (Mustard, 1955).

Perfusion as a means of preserving the viability of the isolated organ prior to transplantation has been widely explored in the kidney and liver but has been attended with little success in the lung. The development of subpleural haemorrhages, $\tilde{O}$ pulmonary oedema, and extravasation of blood $\underset{\omega}{N}$ into the alveoli with rupture of pulmonary $O$ capillaries and perivascular haemorrhage has been

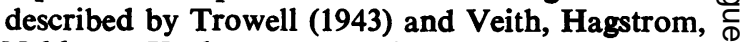
Nehlsen, Karl, and Deysine (1967); identical $\stackrel{\odot}{+}$ changes have been noted in the present series of 0 experiments. Veith et al. drew attention to the $\bar{O}$ similarity between these lesions and those seen in deaths after cardiopulmonary bypass ascribed to 'pump lung'. Many theories have been advanced to explain this destruction of the pulmonary 
vascular bed. An increase in pulmonary vascular resistance, probably due to capillary vasoconstriction, leading to a reduction in blood flow and gaseous exchange is suggested by Veith. It is of interest that signs of pulmonary oedema were noted in the present experiments before any elevation of the pulmonary artery pressure could be detected, and this elevation did not occur on every occasion. Attempts to produce pulmonary vasodilatation by vagal stimulation and Phenergan were not attended by prolonged perfusion times.

Could there be arteriovenous shunting with anoxia of the capillaries distal to the shunts? $\mathrm{Po}_{2}$ gradients between the inspired gases and the pulmonary venous blood were measured and no such shunts could be demonstrated.

It might be argued that interruption of the bronchial circulation is responsible for these changes, but no such lesions are found after sleeve resection of the bronchus or pulmonary reimplantation. Awad, Lemieux, and Lou (1966) found that in a series of lungs perfused in situ pulmonary oedema occurred later in those in which the bronchial vessels had been divided.

The theoretical advantage of the apparatus described above is that the same pressures would be applied to the respiratory and vascular components of the lung, and gradients between the pulmonary capillaries and the alveoli would be reduced to a minimum. Even with this advantage, and pressures maintained at physiological levels, gross pulmonary oedema occurred in both the experimental and the control series.

The most favourable circumstances for prolonged perfusion are provided by a blood/low molecular weight dextran prime, normothermia, mounting the lung in a vertical position, and positive pressure inflation.

While it has been shown that the use of hypothermia (Hardy, Eraslan, and Dalton, 1963) or hyperbaric oxygen and hypothermia (Blumen- stock, Lempert, and Morgado, 1965 ; Largiader, Manax, Lyons, and Lillehei, 1965) is superior to perfusion techniques in maintaining the viability of the isolated lung, the lesions produced by perfusion would repay further study as a means of gaining a greater understanding of pulmonary physiology and of the similar changes encountered in human pathology.

I am grateful to Dr. Donald Heath for his interpretation of the histological appearances, to Dr. Gordon Cumming for helpful advice, and to Mr. T. F. Dee for the photographs.

This project was aided by a grant from the Medical Research Council. The paper is based on a communication presented to the Autumn 1966 Meeting of the Surgical Research Society.

\section{REFERENCES}

Awad, J. A., Lemieux, J. M., and Lou, W. (1966). Fulmonary complications following perfusion of the lungs. J. thorac. cardiovasc. Surg., 51, 767.

Blumenstock, D. A., Lempert, N., and Morgado, F. (1965). Preservation of the canine lung in vitro for 24 hours with the use of hypothermia and hyperbaric oxygen. Ibid., 50, 769.

Daly, I. de Burgh, Linzell, J. L., Mount, L. E., and Waites, G. M. H. (1954). Pulmonary vasomotor responses and acid-base balance in perfused eviscerated dog preparations. Quart. J. exp. Physiol., 39, 177.

Fritts, H. W., Strauss, B., Wichern, W., and Cournand, A. (1963). Utilization of oxygen in the lungs of patients with diffuse, nonobstructive pulmonary disease. Trans. Ass. Amer. Phycns, 76, 302.

Halpern, B., Hamburger, J., and Cruchaud, S. (1948). Action préventive d'un antihistaminique dérivé de la thiodiphénylamine sur l'oedème aigu du poumon expérimental. Sem. Hôp. Paris, 24,656 .

Hardy, J. D., Eraslan, S., and Dalton, M. L. (1963). Autotransplantation and homotransplantation of the lung: further studies. $J$. thorac. cardiovasc. Surg., 46, 606.

Largiader, F., Manax, W. G., Lyons, G. W., and Lillehei, R. C. (1965). In vitro preservation of canine heart and lung. Arch. Surg., 91, 801.

Mustard, W. T. (1955). Clinical and experimental experience with homologous and heterologous lung perfusion. Trans. Amer. Soc. Art. intern. Organs, 1,94.

Trowell, O. A. (1943). The histology of the isolated perfused lung. Quart. J. exp. Physiol., 32, 203.

Veith, F. J., Hagstrom, J. W. C., Nehlsen, S. L., Karl, R. C., and Deysine, M. (1967). Functional, hemodynamic and anatomic changes in isolated perfused dog lungs; the importance of perfusate characteristics. Ann. Surg., 165, 267.

West, J. B., Dollery, C. T., and Naimark, A. (1964). Distribution of blood flow in isolated lung; relation to vascular and alveolar pressures. J. appl. Physiol., 19, 713. 